\title{
TAILOR-MADE CRANIOPLASTY USING CAD-CAM TECHNOLOGIES
}

\section{László Lovas ${ }^{1}$, Dusán Vitanovics ${ }^{2}$}

${ }^{1}$ Department of Vehicle elements and Vehicle structure analysis, Budapest University of Technology and Economics

${ }^{2}$ National Institute of Neurosciences, Budapest

lovas@kge.bme.bu

\begin{abstract}
Treatment of traumatic head injuries and various neurosurgical conditions sometimes includes a removal of a large part of the cranial bone. Later on, the formed crane window must be closed with an implant. In this paper we present a method that allows producing implants of any size and complexity, with accurate fit and relatively low manufacturing cost. The implants are finalized upon virtual verification and need short operations to built in the cranial bone. The method can be used also for changing existing implants.
\end{abstract}

Keywords: crane, reconstruction, CAD

\section{Introduction}

In case of certain diseases or injuries of the head it is necessary to remove a part from the cranial bone. The cranial defect is closed either with autogenous bone or with alloplastic material. Theoretically the use of autogenous bone should be better for the patient. However, in the practice various problems (bone necrosis, bone absorption) may occur in this case. When alloplastic material is used, the cranial defect is closed with metal (ex.: titan) or plastic material (polymer). One of these mentioned polymers is the polymethyl-metacrylate (PMMA). This material is not only cheap, but also easy to model with thus implants of various shape can be realized. Upon the literature, infection type post operational complications appear in 13,3-13,8\% of the cases. ${ }^{1}$ Removal of the implant is necessary in $4,4-12,5 \%$ of the cases. ${ }^{1}$

\section{Methods}

In the early 80 's the implant was realized by melting the half polymerized PMMA directly on the bone window during the operation. The polymerization of plastic material finished in situ on the crane. The heat produced by the process was removed through continuous cooling of the implant. $^{2}$

A typical implant making method used by Hungarian surgeons is shown in Figure 1. Here a rough implant model is realized by melting PMMA on the hairy skin. From this model a negative mould is made. A raw implant model is mould in the negative during operation. When the access to the bone window is free, the surgeon takes the half-polymerized implant, and forms it so to fit the window. The final implant shape and precision depend on the skills of the surgeon, and can not be predicted.

Later, more developed methods used series of CT images. From these image series CAD model of the cranial bone was constructed. From the crane model the CAD model of the implant has 
been created either using mathematical logical operations, or using a large database of CTextracted CAD crane models. Precise fit of the implant model has been verified by comparison to the original CT images. Then a rough implant was realized using CAM techniques. After finishing, a casting mould was made from the rough implant. The final implant was melt in the mould and implanted after polymerization. ${ }^{3}$ Often, even the crane model has been manufactured with CAM technology for easier operation planning and implant shape verification. ${ }^{4}$

One of the first papers in Hungarian medical literature treating of the CAD-CAM method application in implant realization has appeared in $1995 .^{5}$ In the late 1990's researchers have developed the possible methods for realizing a CAD implant model, and advantages and disadvantages of such methods have been shown. Such research results are summed up for example in the 2003 paper of Hieu et al. $^{6}$ In case of small implants, model is realized using the principle of symmetry, while in case of large implants, model is based on a crane of similar shaped crane extracted from a database. These methods are easy to algorithmize. With an appropriate software based on such algorithms a simple implant model can be realized in 6-8 hours. If the implant is larger than the half of the cranial bone, or it passes through the symmetry plane of the crane, or it covers irregularly placed crane windows, then modeling still needs large quantity of manual work. ${ }^{6}$ In such cases the skills of the implant model maker, and the cooperation among the medical doctor, the model maker (CAD) and the manufacturer (CAM) are of great importance.

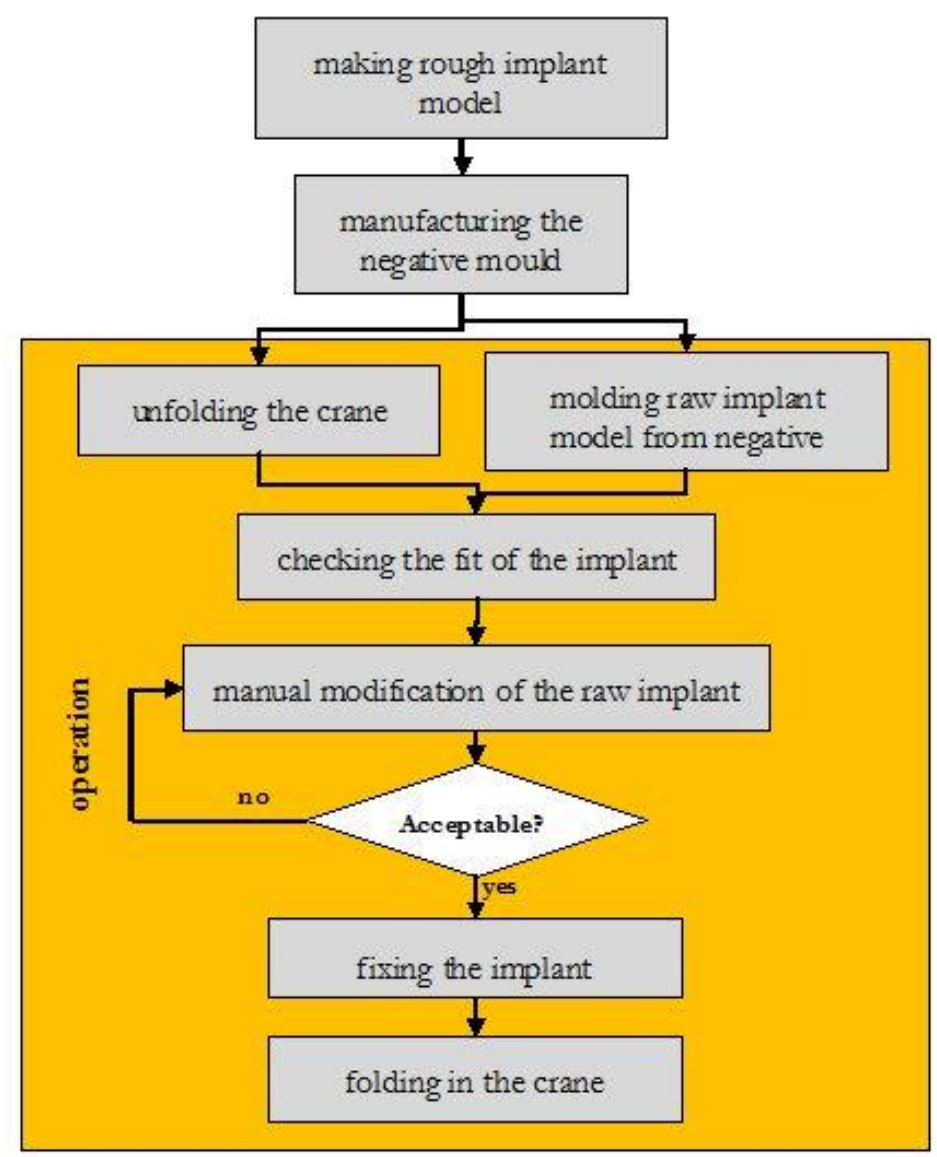

Figure 1. A traditional method for making PMMA implants 


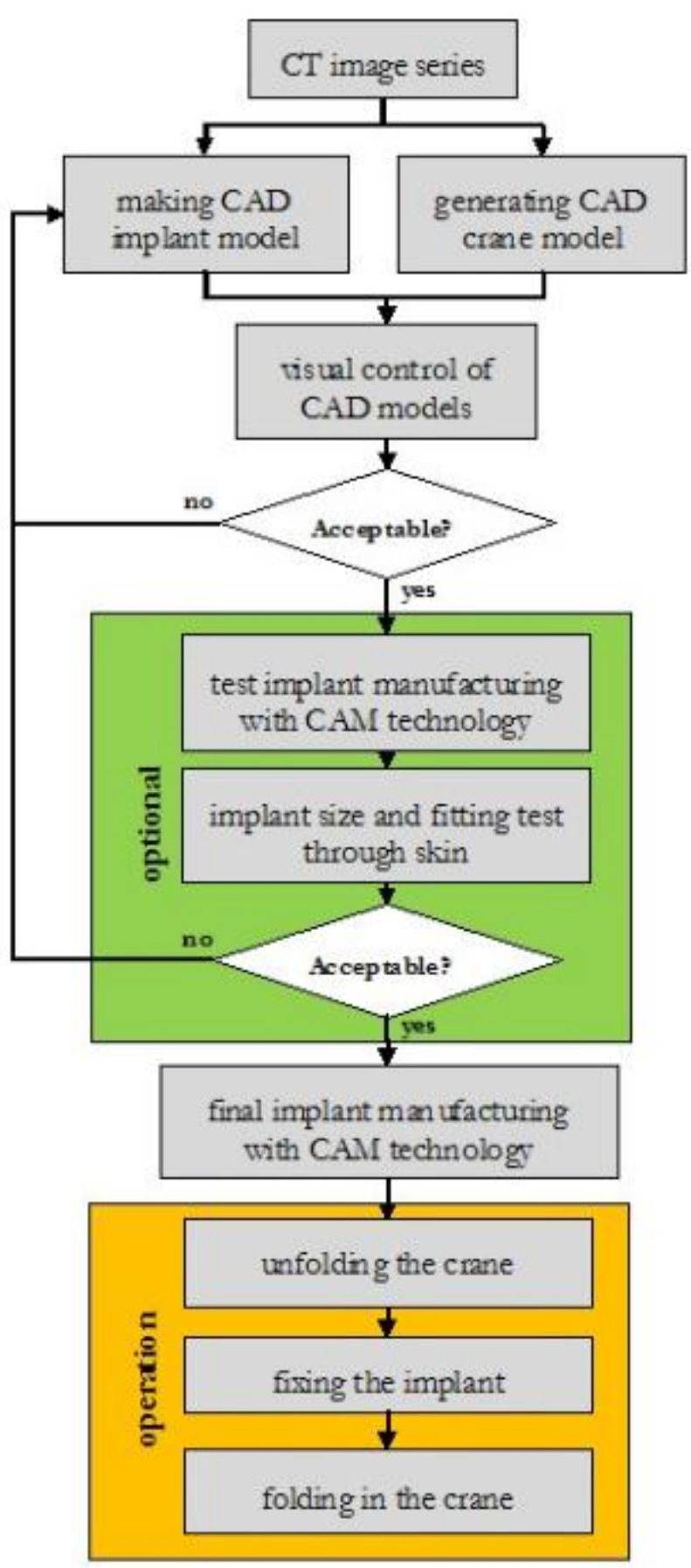

Figure 2. The developed CAD-CAM implant manufacturing process

All of the procedures using CAD designed implants are well proven, and there is large practical experience behind them. We wanted to develop such design process that is more precise and more cost efficient. Our priorities were the following:

- $\quad$ implant design based directly on the CT images (precision)

- $\quad$ implant model control directly in CAD environment (cost efficiency) 
- $\quad$ minimal use of CAM technology (cost efficiency)

- $\quad$ minimal operation time (cost efficiency, patient less exposed to surgery)

Instead of PMMA, ultra high molecule-weight polyethylene (UHMW-PE) was chosen as implant material. This material is a very rigid, non corrosive, non toxic thermoplastic. It is relatively cheap and has good radiological transparency.

The steps of the developed implant manufacturing process are shown in Figure 2. Implant models are built manually, in cooperation of the CAD engineer and the medical doctor. The implant limit surface follow closely the real cranial bone window contour. Example of generated crane model is shown on Figure 3. The taylor-made implant can be seen in Figure 4. Note that optional verification loop can be added to the algorithm if the CAD engineer is beginner or the implant shape is too complex. For simpler implants or with professional engineer the optional loop can be omitted. Example of implant fixation is shown in Figure 5. The implant and the crane are linked with small titanium sheets fixed by screws both on the crane and the implant.

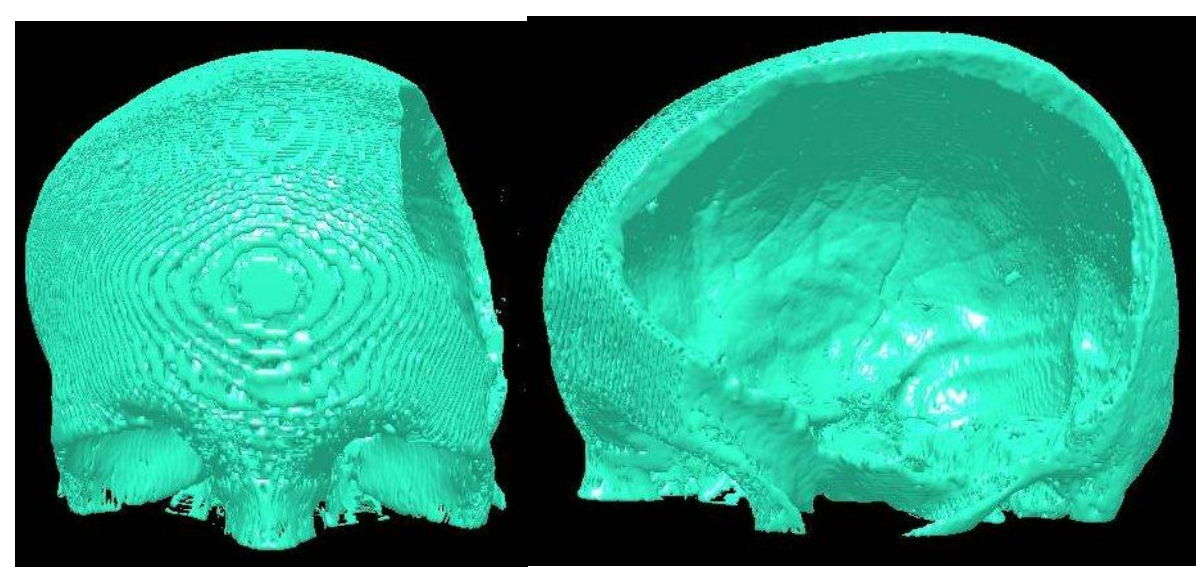

Figure 3. Crane model

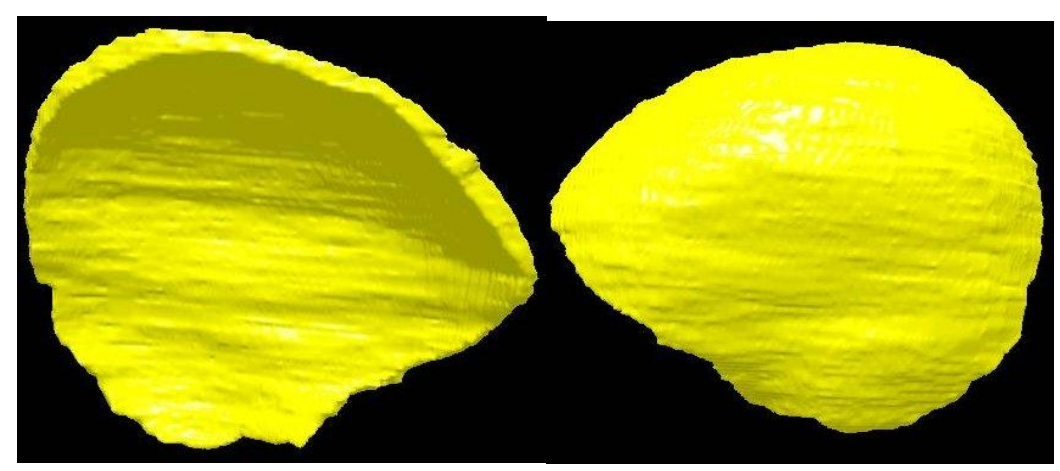

Figure 4. Implant model 


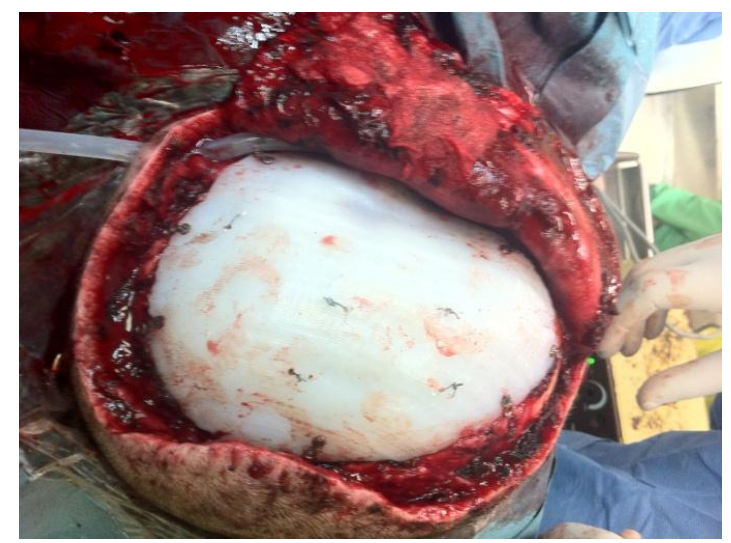

Figure 5. Fixing the implant

The advantage of the manual method is that implant models of any shape, size or complexity can be realized in good quality. The disadvantage of the method is that the time needed for building a model is always more that building a model automatically by software.

\section{Discussion}

22 implants realized with the developed CAD-CAM manufacturing procedure were applied in 19 patients in the last 8 years. None of the implants had to be modified during the operation, all fit perfectly the bone window. Short time post operational complications appeared at 2 patient $(9 \%)$. Long time post operational complications appeared at only 1 patient, where one of the two implants had to be removed $(4,5 \%)$.

After recovery, the presence of implant on the crane is not perceptible (Figure G). Aesthetical problems were not signaled by the patients.

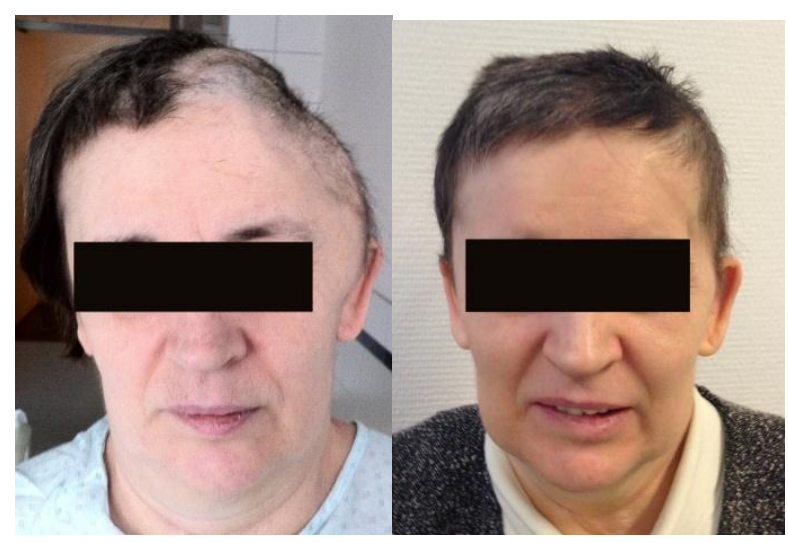

Figure 6. Head shape before and after cranioplasty

The developed CAD-CAM implant manufacturing procedure can also be applied when a previous implant is not convenient, is damaged, moved away or broken. Changing of a previous damaged polymer implant can be realized in one operation: the old implant is removed, and the 
tailor made new is implanted (Figures 7-8.). The procedure was successfully applied also for changing problematic, infected old implants.

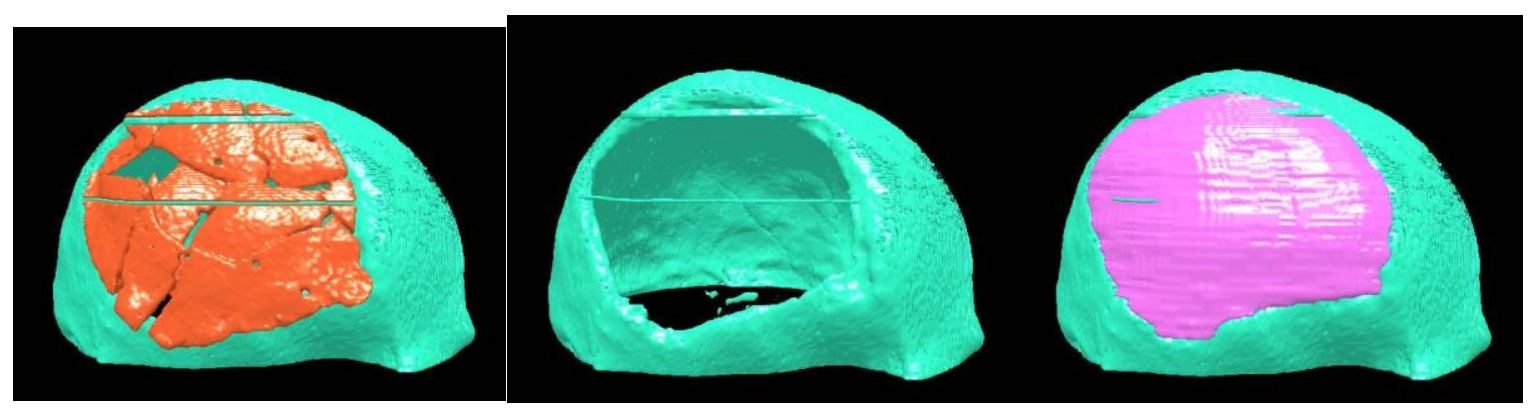

Figure 7. Steps of CAD correction: broken old implant, clean crane window, new implant fit
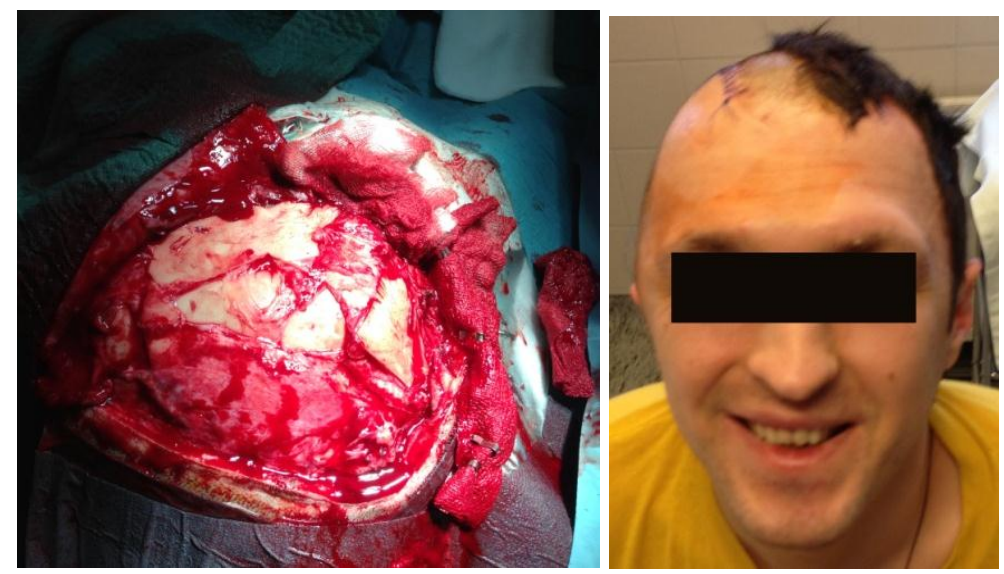

Figure 8. Broken old implant and head shape with new implant

\section{Conclusion}

The elaborated procedure allow to realize tailor made precise implants at relatively low cost. As manual method is used, it is better applied for implants of complicated shape or big size. Upon the experiences, the risk of post-operative problems is not higher than the usual.

\section{REFERENCES}

1. Cabraja M, Klein M, Lehmann TN. Long-term results following titanium cranioplasty of large skull defects. Neurosurgical Focus 2009;26(6):E10,1-7.

2. Marchac D, Greensmith A. Long-term experience with methylmethacrylate cranioplasty in craniofacial surgery. Journal of Plastic, Reconstructive \& Aesthetic Surgery 2008;61:744-52.

3. Goh RCW, Chang CN, Lin CL, Lo LJ. Customised fabricated implants after previous failed cranioplasty. Journal of Plastic, Reconstructive \& Aesthetic Surgery 2010;63:1479-84.

4. Hieu LC, Zlatov N, Vander Sloten J, Bohez E, Khanh L, Binh PH, Oris P, Toshev Y. Medical rapid prototyping applications and methods. Assembly Automation 2005; 25(4):284-92. 
5. Gulyás G, Pulay Gy, Volant M, Bárdosi Tné, Farkas G, Juharosi Z. Koponyacsontpótlás számítógép segítségével készített implantátummal. Orvosi Hetilap 1995;136:2393-97.

6. Hieu LC, Bohez E, Vander Sloten J, Phien HN, Vatcharaporn E, Binh PH, An PV, Oris P. Design for medical rapid prototyping of cranioplasty implants. Rapid Prototyping Journal 2003;9(3):175-86. 